\title{
Cancer family syndrome: cytogenetic investigations, in vitro tetraploidy, and biomarker studies in a large
} family

Ginevra Guanti, Francesco Susca, Giuseppe Cristofaro, Maria Lucia Caruso, Serafina Massari, Rosa Porsia, Alessandro Stella, Italo Giorgio

\begin{abstract}
Fifty-five members of a family with the cancer family syndrome (CFS) were investigated for the following potential biomarkers for cancer proneness: (1) cytogenetics of peripheral blood lymphocytes and skin fibroblasts; $(2)$ in vitro tetraploidy of dermal fibroblast monolayer cultures; (3) quantitative serum immunoglobulin determinations; (4) study of genetic linkage with respect to eight blood group markers including Kidd.

Biological specimens were obtained from 14 patients affected with cancer, 21 subjects at risk, and 20 healthy subjects. None of the markers tested in this family, in order to identify a biomarker for the status of CFS gene carrier, was found to be useful. Our search for linkage to other biological markers (DNA RFLPs and NK cells) is in progress.
\end{abstract}

Colon cancer is the second most common internal malignancy. About 5 to $10 \%$ of all colon cancers have been estimated to occur in families with an inherited susceptibility, as seen in Gardner's syndrome, familial polyposis coli, Turcot's syndrome, and Lynch's syndrome types I and II. Investigation of such families may help us to understand the aetiology of malignancy and help in selecting subjects at risk for more intensive surveillance and earlier detection of tumours.

We report here the results of a series of genetic

Istituto di Genetica, Università degli Studi, Via G Amendola 165/A, 70126 Bari, Italy.

G Guanti, S Massari, R Porsia, A Stella

Istituto Scientifico Gastroenterologico De Bellis, Castellana, Italy.

F Susca, G Cristotaro, M L Caruso, I Giorgio

Correspondence to Dr Guanti.

Received for publication 9 Octoher 1989

Revised version accepted for publication I February 1990. studies on a large family with a hereditary predisposition to non-polypotic colon cancer syndrome or Lynch's syndrome type II. ${ }^{1}$ Its main features include early age of onset of tumours, increased frequency of adenocarcinomas of the colon, mainly proximal location of colorectal tumours, a high occurrence of gastric, endometrial, and multiple primary malignancies, and an autosomal dominant mode of inheritance of the susceptibility to colorectal and other neoplasias.

Potential markers for cancer proneness, ${ }^{2}$ that is, cytogenetic studies of peripheral lymphocytes, in vitro tetraploidy of dermal fibroblast monolayer cultures, quantitative serum immunoglobulin determinations, and red cell blood groups, were investigated in this study.

\section{Materials and methods}

The family was identified by one of us (GC) in 1985 when a 26 year old subject reported that many relatives had colon cancer. Once informed, the consenting members of the family were interviewed and all available medical and other vital records reviewed. Retrospective clinical data were obtained from interviews with members of the fourth and fifth generations, who identified the names of members of the first and second generations. Medical records and pathology documents were then retrieved from physicians as well as hospitals throughout the geographical catchment area where the majority of the family lived. The relative lack of population mobility among this kindred, coupled with availability of medical records in the area, made possible clinical and pathological documentation on relatives with or without cancer. The same members were then offered a clinical examination, gastroscopy and colonoscopy, and laboratory analyses. Several subjects accepted and were evaluated accordingly. The diagnosis of persons in generation VII of the family was provisional because most of them were children under the age of puberty or under the age of risk. The pedigree is shown in the figure. The clinical phenotypes have been previously published. ${ }^{3}$

In order to investigate the possible existence of 


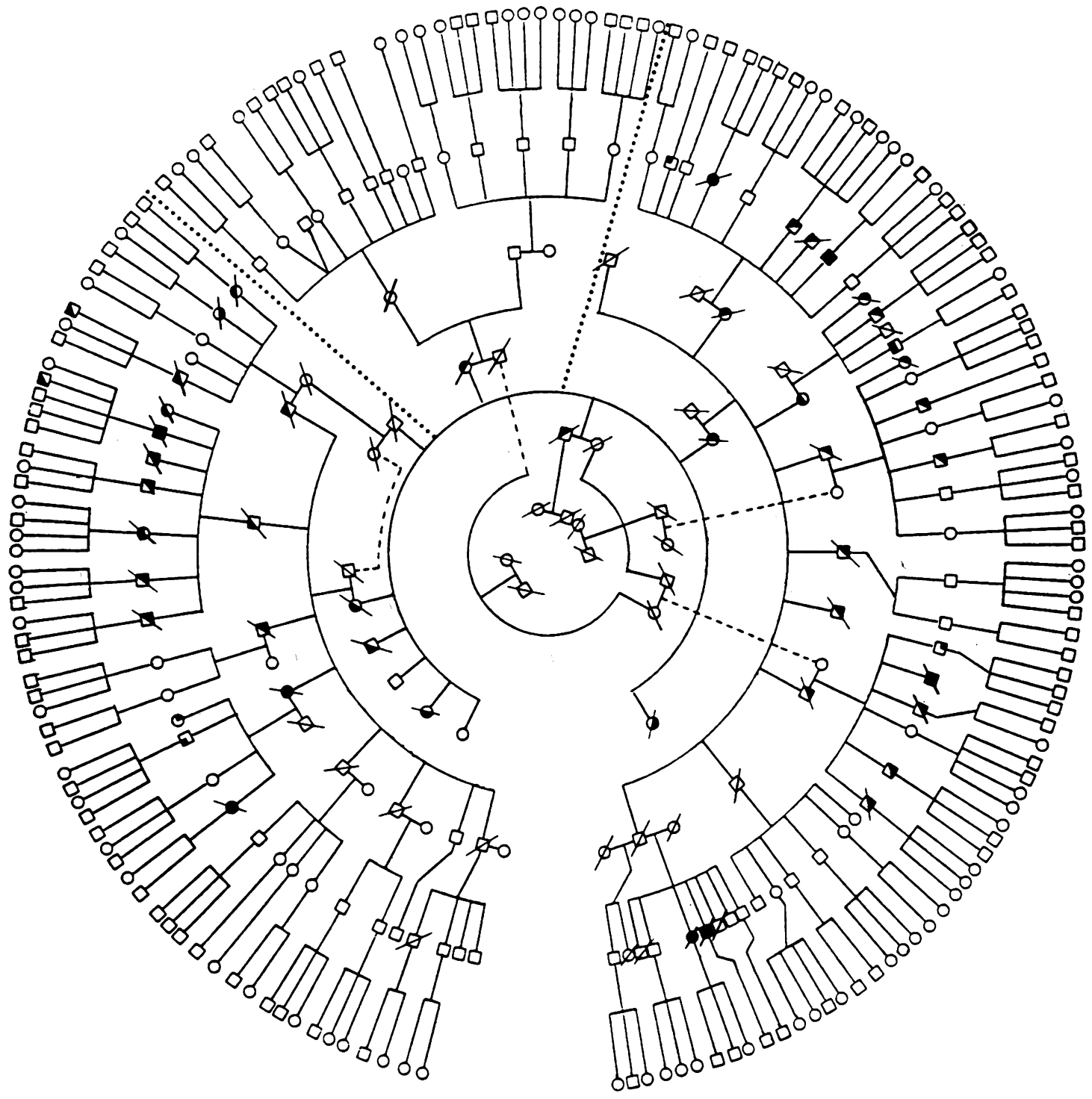

$$
\begin{aligned}
& \text { D Colorectal cancer } \\
& \text { [D Colorectal polyps } \\
& \text { Cancer in multiple sites } \\
& \Xi \text { Gastric polyps }
\end{aligned}
$$

Family pedigree. The dotted lines mark an area not studied.

constitutional or acquired chromosomal changes in the cancer prone subjects, we analysed 55 members of the family. Biological specimens were obtained from: (1) 14 patients with a history of cancer, but asymptomatic at the time as a result of previous surgical treatment; (2) 21 subjects at risk, that is, members who were unaffected but at risk ( $50 \%$ probability) of carrying the CFS gene since cancer had occurred in a first degree relative; (3) 20 healthy subjects, that is, those who were over the at risk age for this cancer 
Table 1 Incidence of the major heterochromatic z'ariants.

\begin{tabular}{|c|c|c|c|c|c|c|}
\hline & \multirow{2}{*}{$\frac{\text { Chromosome } 1}{\mathrm{~h}+}$} & \multicolumn{2}{|c|}{ Chromosome 9} & \multirow{2}{*}{$\frac{\text { Chromosome } 16}{\mathrm{~h}+}$} & \multirow[b]{2}{*}{ Breaks } & \multirow[b]{2}{*}{ Gaps } \\
\hline & & ins & $\mathbf{h}+$ & & & \\
\hline $\begin{array}{l}\text { Cancer patients }(n=14) \\
\text { Healthy family members }(n=20) \\
\text { At risk subjects }(n=21) \\
\text { Acquired family members }(n=26) \\
\text { Controls }(n=50)\end{array}$ & $\begin{array}{l}1(5 \%) \\
1(48 \%) \\
1(3 \cdot 8 \%) \\
+(8 \%)\end{array}$ & $\begin{array}{l}1\left(5{ }^{\prime \prime}\right) \\
1(48 \%) \\
1(3 \cdot 8 \%) \\
3\left(6{ }^{\prime \prime}\right)\end{array}$ & $\begin{array}{l}1,7 \cdot 1 " 10) \\
2(10 " 1) \\
1(5010) \\
5\left(10^{\prime \prime}\right)\end{array}$ & $\begin{array}{l}1\left(\overline{50^{\prime \prime}}\right) \\
\overline{\left(3 \cdot 8^{\prime \prime}\right.} \\
3\left(6^{\prime \prime}\right)\end{array}$ & $\begin{array}{l}1 \cdot 8 " 11 \\
1 \cdot 7 " 11 \\
2 \cdot 0 " 11 \\
1 \cdot 9 \% " \\
1 \cdot 99^{\prime \prime \prime}\end{array}$ & $\begin{array}{l}3 \cdot 2010 \\
2 \cdot 7 " 1 " \\
2 \cdot 201 \\
4 " 10 \\
3 " 10\end{array}$ \\
\hline
\end{tabular}

h+ =increased pericentromeric heterochromatin. inv = pericentromeric inversion.

family; and (4) 26 normal controls, including unrelated persons who had married into the family or persons belonging to cancer free families.

Chromosomal analysis was performed with conventional $\mathrm{G}$ and $\mathrm{C}$ banding. Prometaphase chromosomes were prepared essentially according to the method of Viegas-Pequignot and Dutrillaux. ${ }^{+}$Twenty-five metaphases were analysed for each subject with each different technique (when abnormal cells were seen, 100 metaphases were examined). Heterochromatin polymorphism was presumed to exist when, according to Lynch et al, inversion or abnormally large amounts were present in the pericentromeric regions of chromosomes 1,9 , and 16. For the purpose of this study, only apparent chromosomal variants of constitutive heterochromatin regions of chromosomes 1,9 , and 16 were recorded. The classification suggested by Patil and Lubs ${ }^{5}$ was used. All the samples were coded so that the study was performed blind. The results obtained from the members of the affected family were compared with the findings of a previous study carried out on 25 normal, healthy couples and 308 couples with recurrent abortion. ${ }^{6}$

Fibroblast cultures were established from upper arm skin biopsies and maintained in Ham's F12 medium supplemented with pen-strept antibiotics and $10 \% \mathrm{FCS}$ in $5 \% \mathrm{CO}_{2}$. The first outgrowth of the biopsy specimens was defined as passage 1. Every following passage roughly corresponded to one population doubling. The cells were grown in culture from eight to 15 weeks (three to six subcultures), before carrying out in vitro studies. The frequency of proliferating hyperdiploid or tetraploid cells was determined by counting the chromosomes from 100 randomly selected mitoses.

Serum immunoglobulins of the IgA, IgG, and IgM classes were quantified with commercial radial immunodiffusion plates.

The red cell antigens typed were $\mathrm{ABO}, \mathrm{Rh}, \mathrm{MNSs}$, Duffy, Kell-kp, Kidd, Lewis, and P.

Linkage analysis was performed using the computer program LIPED assuming an autosomal dominant mode of inheritance, a penetrance of $93 \%$, and a gene frequency of $5 \times 10^{-5}$. Using the method of Alm and Licznerski, ${ }^{7}$ penetrance was estimated by counting the number of affected and unaffected parents in whose progeny colorectal cancer was diagnosed. The gene frequency was calculated by the formula $f=P / D$ where $\mathrm{P}$ is the number of patients with CFS who died in a given interval of time and $D$ the number of all deaths in the general population during the same time.

The probability of displaying the affected phenotype was dependent on age. We therefore applied an age of onset correction using a straight line correction between ages 20 and 60 (age of onset in this family ranged from 25 to 55 ). This means that people under 20 contribute little information to the linkage analysis.

\section{Results}

The cytogenetic studies on peripheral blood lymphocytes, even when a high resolution chromosome banding technique was used, failed to show the presence of any kind of alteration. The incidence of heterochromatin polymorphisms including inversions was not significantly increased in the members of the CFS family as compared with controls (table 1). No detectable structural abnormalities were observed in the chromosomes of skin fibroblasts.

The incidence of tetraploid metaphases in cultures

Table 2 Lod scores at selected recombination fractions between CFS and blood group markers.

\begin{tabular}{lrrrrr}
\hline & \multicolumn{5}{c}{ Recombination fraction } \\
\cline { 2 - 6 } Marker & \multicolumn{1}{c}{0.05} & \multicolumn{1}{c}{0.10} & 0.20 & \multicolumn{1}{c}{0.30} & \multicolumn{1}{c}{0.40} \\
\hline ABO & 0.12 & 0.40 & 0.46 & 0.30 & 0.11 \\
Rh & 0.05 & 0.28 & 0.34 & 0.18 & 0.02 \\
MNSs & -2.40 & -1.20 & -0.42 & -0.11 & -0.03 \\
Kell & -2.10 & -1.23 & -0.80 & -0.49 & -0.20 \\
Lewis & 0.31 & 0.56 & 0.55 & 0.28 & 0.07 \\
Duffy & 0.12 & 0.28 & 0.30 & 0.19 & 0.04 \\
Kidd & -0.70 & -0.48 & -0.16 & -0.05 & -0.01 \\
P & -1.60 & -0.37 & -0.15 & -0.02 & 0.00 \\
\hline
\end{tabular}

Table 3 Serum immunoglobulin lecels $(\mathrm{mg} / 100 \mathrm{ml})$.

\begin{tabular}{lrll}
\hline & \multicolumn{1}{c}{ IgG } & \multicolumn{1}{c}{$\operatorname{IgA}$} & IgM \\
\hline Healthy subjects & $1235(345)$ & $254(138)$ & $149(50)$ \\
Cancer patients & $990(283)$ & $236(72)$ & $138(41)$ \\
At risk subiects & $962(181)$ & $184(74)$ & $161(64)$ \\
Controls & $1067(248)$ & $211(101)$ & $102(48)$ \\
\hline
\end{tabular}

Values are expressed as mean (SD).

Student's $t$ test was not significant in any case. 
derived from 10 controls without a family history of cancer ranged from 0 to $7 \%$. The percentage of cells showing tetraploidy was within the normal range $(0$ to $7 \%$ ) in all the lines derived from the skin biopsies of the CFS family members, apart from two at risk subjects who exhibited values of $7 \cdot 9 \%$ and $14 \%$, respectively. As a positive control, two fibroblast cultures from a FAP (familial adenomatous polyposis) carrier displayed a $41 \%$ tetraploidy.

None of the eight blood groups typed (ABO, Lewis, Rhesus, MNSs, Duffy, Kell, Kidd, and P) showed a statistically significant lod score in the linkage analysis (table 2).

Normal immunoglobulin concentrations were found in the serum of all the subjects tested (table 3).

\section{Discussion}

The medical consequences of CFS can be devastating. During genetic counselling, gene carriers, that is, those affected with cancer, discover that they have a $50 \%$ probability of transmitting the abnormal gene to their offspring. Furthermore, many subjects in families with CFS cannot be definitely included or excluded as gene carriers because of their youth and the variable age of onset of the disease. Thus, the identification of markers is imperative in order to improve genetic counselling.

According to Lynch's suggestions, the family was investigated for the following potential biomarkers of genotype status: (1) cytogenetics of peripheral blood lymphocytes; (2) quantitative serum immunoglobulin levels: (3) study of genetic linkage with respect to blood group markers; and (4) in vitro tetraploidy of dermal fibroblast monolayer cultures.

The constitutional karyotypes of all members of the family under study were normal even in respect to the spontaneous presence of gaps, breaks, and fragments. Furthermore, there was no evidence of the presence of heterochromatin polvmorphisms, which have been suggested are connected with malignancy. ${ }^{8-10}$

Although we recognise the importance of examining even small chromosomal alterations, taking into account the increasing role that chromosomal rearrangements are assuming in the aetiology of malignancy, ${ }^{11-1+}$ we are doubtful about the role of heterochromatin polymorphisms as we lack the objective criteria for their evaluation and interpretation.

Increased in vitro tetraploidy or hyperdiploidy in dermal fibroblast monolaver cultures was reported by Lynch et $a l^{15}$ in 22 colon cancer patients belonging to 11 different families, and in four melanoma patients from two families with dysplastic naevus syndrome. The family under study here did not confirm these findings. Although slight differences in experimental conditions can influence results, this was not the case here, since the first series of biopsies was performed by a collaborator of Professor Lynch and the cultures were harvested in the medium (TC-10) kindly supplied by him.

Quantitative serum IgA, IgM, and IgG immunoglobulin levels fell into the normal range in each of the three groups (affected, normal, and at risk subjects) analysed. These immunological parameters have been investigated and reported in several papers, ${ }^{16}$ but the widely controversial results frustrate any attempt to find a single unifying explanation.

The CFS gene was not found in linkage to any of the blood groups typed: therefore the association of the Kidd group with the expression of the syndrome described by Lynch $e t a l^{2}$ cannot be confirmed.

Since the biomarker findings are a major advance in the understanding of CFS and represent, at the moment, the only way of distinguishing between who will and will not manifest the phenotype (that is, cancer), our search for linkage to other biological markers (DNA RFLPs and dosage of natural killer cells) is in progress. ${ }^{17}$

The authors would like to thank Dr Guy Schuelke for help with some of the tissue culture experiments and Professor H T Lynch for helpful suggestions. The authors are especially grateful to the members of the family for their continuing cooperation throughout these investigations. This work was supported by grants from Consiglio Nazionale delle Ricerche (no 87.00857 .51 ), $40 \%$ and $60 \%$ MPI, Ministero della Sanità, Associazione Italiana Ricerca sul Cancro.

I Lunch HT, Kimberling W, Albano WA, 't al. Hereditary nonpolyposis colorectal cancer (Iynch syndromes I and II). I Clinical description of resource. Cancer 1985:56:934-8.

2 Lvnch HT, Schuelke GS, Kimberling WJ, it al. Hereditary nonpolyposis colorectal cancer (Lynch syndrome I and II). II Biomarker studies. Ciancer 1985;56:939-51.

3 Cristofaro G, Lynch HT, Caruso ML. it al. New phenotvpic aspects in a family with Lynch syndrome II. Ciamier 1987;60 51-8.

+ Viegas-Pequignot E. Dutrillaux B. Une methode simple pour obtenir des prophases et des prometaphases. Ann (iene't $l^{\text {Paris }}$ 1978:21:122-5

5 Patil SR, Lubs HA. Classification of 4 h regions in human chromosomes 1,9 and 16 by $\mathrm{C}$ banding. Hum (ienet 1977:38: 35-8.

6 Susca F. Porsia R, Cascone A. et al. Chromosome studies of 308 couples with recurrent abortion. In: Giovannucici ML, ed. International simposium: From ge'ne' to man and from man to ge'ne'. Firenze: Permanent Committee for Identitication of Malformation Syndromes, 1988:56-60.

$7 \mathrm{Alm}$ T, Licznerski $\mathrm{G}$. The intestine polyposss. Cim (iastroenterol 1973:2:577-602

8 Atkin NB, Brito-Babapulle V. Heterochromatin polymorphism and human cancer. Cancer (j'net Civtogenet 1981;3:261-72.

9 Chudina AP Selchuk VJ, Akulenko LV. C-heterochromatin variants in patients with primary malignant neoplasms. Clin (inn't 1981:19:497

10 Shabtai F, Antebi E, Klar D, Kimchi D, Hart J, Halbrecht I Cytogenetic study of patients with carcinoma of the colon and rectum: particular C-band variants as possible markers for cancer proneness. Cancer Genet Civtogene't 1985:14:235-45.

11 Yunis J], Ramsay N. Retinoblastoma and subband deletion of chromosome 13. Am f Dis Child 1978:132:161-3.

12 Cavenee WK. Dryja TP. Phillips RA, 't al. Expression of 
recessive alleles by chromosomal mechanisms in retinoblastoma. Nature 1983;305:779-84.

13 Herrera L, Kakati S, Gibas L, Pietrzak E, Sandberg AA. Gardner syndrome in a man with an interstitial deletion of $5 \mathrm{q} . \mathrm{Am} \mathcal{J}$ Med Genet 1986;25:473-6.

14 Bodmer WF, Bailey CJ, Bodmer J, et al. Localization of the gene for familial adenomatous polyposis on chromosome 5. Nature 1987;328:614-6.

15 Lynch HT, Fusaro RM, Danes BS, Kimberling WJ, Lynch WC. A review of hereditary malignant melanoma including bio- markers in familial atypical multiple mole melanoma syndrome. Cancer Genet Cytogenet 1983;8:325-8.

16 Schuelke GS, Lynch HT, Chaperon EA. Immunological parameters as possible biomarkers for disclosure of cancer prone genotypes in familial cancers. In: Lynch PM, Lynch HT, eds. Colon cancer genetics. New York: Van Nostrand Reinhold, 1985:187.

17 Guanti G, Massari S, Cristofaro G, et al. Depressed level of natural killer cells in cancer family syndrome. Cancer Immunol Immunother 1989;30:307-11. 